\title{
Análise da influência de Variáveis Socioeconômicas na distribuição de casos e óbitos de Covid-19 no Brasil
}

\author{
Analysis of the influence of Socioeconomic Variables in the \\ distribution of Covid-19 cases and deaths in Brazil
}

\author{
Marco Túlio Mendonça Diniz ${ }^{1}$, Marcos Antonio Cavalcante de Oliveira \\ Júnior"I(I) , Vítor Hugo Campelo Pereira III(I) Glairton Cardoso Rocha"I(1) \\ ' Universidade Federal do Rio Grande do Norte (UFRN), Departamento de Geografia, Caicó, Rio Grande \\ do Norte (RN), Brasil \\ "Instituto Federal do Piauí (IFPI), Piripiri, Piauí (PI), Brasil \\ II' Universidade Federal do Rio Grande do Norte (UFRN), Natal, Rio Grande do Norte (RN), Brasil
}

\section{RESUMO}

O presente artigo tem como objetivo analisar a influência de variáveis socioeconômicas na distribuição de casos e óbitos relacionados a Covid-19 no Brasil. Para isso, foram utilizadas variáveis socioeconômicas referentes aos Índices de Desenvolvimento Humano dos Municípios (IDHM) e suas variações IDHM Renda, IDHM Longevidade e IDHM Educação, bem como os dados epidemiológicos sobre a distribuição de casos e óbitos relacionados a Covid-19 no Brasil na data de 02/06/2020. Com base em testes estatísticos (correlação e regressão) referentes a uma amostra de 200 municípios, os resultados indicaram influência relativa, principalmente do IDHM Renda na distribuição de casos e óbitos relacionados à Covid-19 por 100.000 habitantes. Na porção territorial Norte-Nordeste do Brasil, as áreas com a presença predominante de municípios com baixo IDHM Renda apresentaram também maiores valores de casos e óbitos por 100.000 habitantes, ao passo que na porção territorial Centro-Sul, as áreas com IDHM Renda mais elevado, apresentaram baixos valores de casos e óbitos por 100.000 habitantes. Os resultados também indicaram que os maiores valores de casos e óbitos relacionados à Covid-19 estão fora das Regiões Metropolitanas brasileiras, evidenciando uma disseminação desse vírus para os municípios do interior.

Palavras-chave: IDHM; estatística inferencial; renda; Covid-19 


\section{ABSTRACT}

This article aims to analyze the influence of socioeconomic variables on the distribution of cases and deaths related to COVID-19 in Brazil. To this end, socioeconomic variables referring to the Municipal Human Development Index (MHDI) and their variations MHDI Income, MHDI Longevity and MHDI Education were used, as well as epidemiological data on the distribution of cases and deaths related to COVID-19 in Brazil, at the date of 6/2/2020. Based on inferential statistical tests (correlation and regression) for a sample of 200 municipalities, the results indicated a relative influence, mainly of the MHDI Income on the distribution of cases and deaths related to COVID-19 per 100,000 inhabitants. In the North-Northeast territorial portion of Brazil, the areas with the predominant presence of municipalities with low MHDI Income also presented higher amounts of cases and deaths per 100,000 inhabitants, while in the Center-South territorial portion, the areas with the highest income MHDI, showed low amounts of cases and deaths per 100,000 inhabitants. The results also indicated that the highest amounts of cases and deaths related to COVID-19 are outside the Brazilian Metropolitan Regions, showing a spread of this virus to the hinterland municipalities.

Keywords: MHDI; Inferential statistics; Income; COVID-19

\section{INTRODUÇÃO}

O impacto do número de óbitos por Covid-19 no Brasil e no mundo tem sido objeto de estudo de pesquisas recentes. Estes estudos visam selecionar variáveis que possam ajudar a identificar possíveis causas que interferem positivamente ou negativamente nos números. Observa-se que, em diferentes localidades, tanto o número de infectados quanto o de óbitos apresentam variações e estas devem ser identificadas e explicadas.

Grande parte dessas variações em relação ao número de contaminados como quanto ao número de mortos podem ser explicadas por estudos que dimensionam o impacto de características populacionais, demográficas, políticas, ambientais, socioeconômicas, assim como questões de mobilidade urbana e interurbanas, como por exemplo, o movimento migratório referente a viagens domésticas e internacionais (ALMAGRO; ORANE-HUTCHINSON, 2020), mobilidade urbana interna e entre cidades satélites (FANG; WANG; YANG, 2020).

Este estudo não verifica todas estas caraterísticas citadas acima. Pretendese a analisar características de variáveis socioeconômicas (Índice de Desenvolvimento Humano do Municípios - IDH e suas variações), de mobilidade 
urbana e interurbana ou fluxo migratório através da verificação dentre os municípios selecionados na amostra, aqueles que possuem aeroportos (nacionais ou internacionais) e demográficas a partir da análise da ocorrência de casos e óbitos em municípios localizados em regiões com adensamento populacional, no caso em Regiões Metropolitanas. Fang, Wang e Yang (2020), apontam que a mobilidade humana contribui diretamente para a transmissão de doenças infecciosas e que estas representam ameaças à saúde global.

De acordo com o site oficial do governo brasileiro, o primeiro caso de Covid19 no Brasil foi registrado na cidade de São Paulo, no dia 26 de fevereiro de 2020. O caso foi registrado como de um homem, com idade de 61 anos e com histórico de viagem recente à época para a Itália. Um mês depois, em 26 de março de 2020, haviam sido registrados 2988 casos em todos os estados brasileiros, com 77 mortos. As primeiras mortes foram registradas nos estados de Goiás e Santa Catarina. Em 26 de abril de 2020, o registro foi de 61.888 casos, com 4.205 óbitos. Em 26 de maio de 2020, o governo apresentou 391.222 casos e 24.512 óbitos. Com esses dados de evolução da doença por todo país, diversos questionamentos têm surgido no sentido de explicar ou entender a forma que o vírus tem se apresentado nessas diferentes localidades, ou também, entender quais populações ou grupos são mais vulneráveis à contaminação, quais serviços ou ações públicas podem contribuir para diminuir ou até mesmo ampliar os níveis de contaminação.

Assim, apesar de diversos autores relatarem as dificuldades em prever e em realizar estudos que analisem ações econômicas e sociais que possam reduzir os casos e óbitos de Covid-19 devido ser um período de "incertezas" (ATKESON, 2020; AVERY et al., 2020; JONES et al., 2020; ROWTHORN, 2020), este trabalho tem como objetivo analisar influência de variáveis socioeconômicas na distribuição de casos e óbitos relacionados a Covid-19 no Brasil. 
Para isso observa-se o uso de variáveis sociais relacionadas ao IDHM ${ }^{1}$ (IDH Municípios, IDHM Renda, IDHM longevidade e IDHM Educação), de concentração populacional (identificada pelas regiões metropolitanas), de mobilidade interurbana e interestadual /internacional (aeroportos) com variáveis associadas aos números de casos e óbitos por Covid-19 no território brasileiro. Para isso, o estudo faz uma abordagem quantitativa com uso de estatística inferencial para análise dos dados secundários coletados.

\section{REFERENCIAL TEÓRICO}

Almagro e Orane-Hutchinson (2020) procuram avaliar a relevância de variáveis como comportamento populacional, densidade de comunicação, padrões de deslocamento e ocupações, que explicam as diferentes taxas de contaminação por Covid-19 em Nova York. Apesar da região objeto de estudo apresentar características e padrões demográficos totalmente diferentes do brasileiro a relevância da análise do estudo para este trabalho é a identificação de variáveis demográficas para realização deste. Dentre as variáveis demográficas analisadas neste estudo pode-se citar, raça, gênero, renda, tamanho da família, uso de transporte público. Apresenta como resultado que os deslocamentos diários através de transportes públicos possuem um elevado fator de propagação da doença.

Em outro estudo Coven e Gupta (2020), realizaram uma pesquisa sobre mobilidade urbana na cidade de Nova York, inferindo relações com casos de Covid19. Observa-se que, famílias com padrão de vida mais baixo possuem um potencial de contaminação muito maior que famílias com padrão de vida mais elevado.

\footnotetext{
${ }^{1}$ É uma medida composta de indicadores em três aspectos do desenvolvimento humano: longevidade, educação e renda. O índice varia de 0 a 1 . Quanto maior a proximidade do valor 1, maior 0 desenvolvimento humano.
} 
Assim, para Coven e Gupta (2020), um maior controle da mobilidade urbana contribui positivamente para a redução dos níveis de infecção na população.

Uma outra pesquisa de Fang, Wang e Yang (2020) sobre a relação mobilidade urbana e Covid-19, desta vez na cidade de Wuhan, na China, avaliou o efeito da redução de mobilidade urbana imposta pelo governo como medida de contenção do surto epidemiológico. Como ação identificou-se uma redução de 76,64\% de entradas na cidade e de $56,35 \%$ de saídas. Além disso o movimento urbano na cidade reduziu-se em $54,15 \%$, além da redução do fluxo populacional entre as cidades próximas a Wuhan. Para Fang, Wang e Yang (2020), os níveis de infecção teriam sido consideravelmente superiores se estas medidas não tivessem sido tomadas, principalmente fora da cidade de Wuhan. Assim, além das medidas de redução da mobilidade urbana, medidas de distanciamento social também contribuíram para os resultados alcançados pela cidade e em outras províncias chinesas. Outros estudos apontam que medidas de restrição da mobilidade urbana contribuem positivamente para a redução de infecções ou surtos epidêmicos (BAJARDI et al., 2011; WANG; TAYLOR, 2016; CHARU et al., 2017).

Trabalhos recentes analisam a relação entre renda per capita e o número de casos por COVID-19. Rafael et al. (2020) analisam esta relação (renda per capita e a incidência de casos de COVID-19) em bairros do município do Rio de Janeiro, Brasil, indicando que taxas de incidência de COVID-19 são influenciadas pela renda dos bairros de residência onde os casos são identificados. Teixeira et al. (2020) analisam a incidência e mortalidade por COVID-19 e suas relações com variáveis como renda média per capita, raça e densidade demográfica. Como resultado identificaram uma correlação significativa entre a incidência de casos acumulada e os índices de mortalidade, assim como com a média da renda.

Gilbert et al. (2020) avaliam vulnerabilidade de países africanos em relação ao risco de importação do COVID-19 relacionado a viagens internacionais assim como estimar o risco de contaminação dos países. Macedo (2020) faz um estudo comparativo entre 12 países da América do Sul com o número de infectados e 
mortos por COVID-19 e as relações que mostram a eficiência de ações como isolamento e distanciamento social nos números da pandemia.

Stojkoski et al. (2020) analisam variáveis socioeconômicas que impactam na pandemia. Este estudo analisa através de 29 determinantes que descrevem um conjunto variado de características socioeconômicas, as possíveis explicações para os resultados da pandemia trazendo como contribuição a relevância em entender a ação destes determinantes sobre os efeitos da pandemia, afim de contribuir positivamente para oferecer uma visão que amplie alternativas no desenvolvimento de políticas socioeconômicas que tenham como objetivo a prevenção em futuras crises epidêmicas.

Sannigrahi et al. (2020) identificam que a composição demográfica da população controla as taxas de mortalidade por COVID-19, para o estudo e aplicação do modelo proposto os autores consideraram como variáveis dependentes o número de casos e óbitos por COVID-19. No estudo de Damette e Goutte (2020) os autores analisam algumas variáveis relativas ao grau de infecção por Covid-19, dentre estes aspectos são analisados a intensidade da pandemia, através da representação do número de pessoas infectadas, as estruturas demográficas mais susceptíveis a infecção, analisando para isso a idade dos contaminados, as infra-estruturas de saúde disponibilizadas para a população representado através do número de leitos hospitalares disponíveis, número de médicos e equipe de saúde e o grau de abertura dos países referente a entrada de turistas.

Damette e Goutte (2020) identificaram ainda que o número de chegadas de turistas em determinado país está positivamente relacionado à variável taxa de mortalidade, e que o número de pessoas infectadas também é um preditor significativo da taxa de mortalidade. Como consequência disto o maior número de pessoas infectadas pode, portanto, levar a um efeito de saturação dos serviços de saúde. Assim, na literatura encontram-se estudos que relacionam a entrada de 
turistas e os efeitos de propagação de epidemias, o que se torna uma das bases teóricas para este artigo.

Com isso, algumas variáveis foram selecionadas com objetivo de analisar aquelas que podem interferir de forma positiva ou negativa nos resultados de contaminação e óbitos por Covid-19 no Brasil. Dentre elas, está a análise da relação da chegada de voos internacionais semanais em todos os Estados brasileiros que possuem aeroporto internacional, assim como outras variáveis (mobilidade urbana, densidade demográfica, IDH, número de leitos de UTI).

No artigo Socioeconomic Determinants of COVID-19 Infections and Mortality: Evidence from England and Wales de Sá (2020), o estudo faz uso de correlações simples e análises de regressão para entender número de Casos de Covid-19 e o número de mortes por Covid-19 por 100.000 habitantes, associados a características socioeconômicas. Os resultados apontam que famílias mais numerosas, que utilizam transportes públicos possuem uma maior tendência a infecção. Em relação ao número de mortos, as variáveis, tamanho da família e uso de transportes públicos aparecem com um grau de relevância menor que variáveis como idade, etnia e nível de saúde.

Além disso nas localidades com maior adensamento populacional o índice de mortes é maior. Conclui o estudo apresentando medidas para redução dos níveis de contaminação como aumento das políticas de melhoria das condições sociais como moradia e saúde, além disso com o relaxamento do isolamento social, os governos devem estar atentos a disseminação do vírus por meio dos transportes públicos. Mollalo, Vahedi e Rivera (2020) analisam através de modelagem espacial a relação existente entre 35 variáveis (ambientais, socioeconômicas e demográficas) e a incidência de COVID-19 nos Estados Unidos, trazendo como resultado que um fator socioeconômico como a desigualdade na renda influencia na explicação da incidência de COVID-19 no país.

Assim, no contexto brasileiro de desigualdades em todos os estados e regiões, estudos que abordem temáticas relacionadas a análises demográficas, 
sociais, espaciais e geográficas e que buscam compreender a presença e manifestação do Covid-19 em torno dessas diferenças, tornam-se cada vez mais necessários e hoje é tema central nas discussões acadêmicas em todo o mundo, o que oferece assim estímulos (ou desafios) para a produção de conhecimento e avanço da ciência.

Estudos na área de Geografia buscam avaliar a difusão da Covid-19 no Brasil relacionando aspectos socioeconômicos ou de desigualdade social (FARIA et al., 2020; GUIMARÃES; ELEUTERIO; MONTEIRO-DA-SILVA, 2020). Neste sentido, Orellana et al. (2021) fazem um estudo sobre o número de mortes durante o período de pandemia, associando a fatores como subnotificações e desigualdades regionais. Os autores trazem nos resultados que diferenças socioeconômicas regionais e o acesso aos serviços de saúde influenciaram no número de óbitos por Covid-19 (ORELLANA et al., 2021). Outros estudos atuais procuram evidenciar que a taxa de mortalidade associada a Covid-19 possui uma estreita relação com regiões periféricas ou regiões com graves problemas de desigualdade social (BARRETO et al., 2020; DORN; COONEY; SABIN, 2020; FARIA et al., 2020; SANTOS et al., 2020; WANG; TANG, 2020).

Com isso, a relevância deste estudo está em refletir diante do contexto das desigualdades socioeconômicas brasileiras, em que o estudo adota como variáveis de análise o Índice de Desenvolvimento Humano dos Municípios (Renda, Educação e Longevidade) o adensamento populacional das Regiões Metropolitanas e seus reflexos sobre os números de casos e mortes registrados, de que maneira as políticas públicas podem desenvolver ações que visem a redução dessas desigualdades perante os impactos negativos que estas podem trazer à população frente a situações de pandemia. 


\section{METODOLOGIA}

A pesquisa objetivou analisar a influência de variáveis socioeconômicas na distribuição de casos e óbitos relacionados a Covid-19 no Brasil, verificando para isso possíveis relações estatísticas entre as variáveis sociais relacionadas, IDH (IDH Municípios, IDHM Renda, IDHM longevidade e IDHM Educação), de concentração populacional (identificada pelas regiões metropolitanas), de mobilidade interurbana e interestadual (aeroportos) com variáveis associadas aos números de casos e óbitos por Covid-19 no território brasileiro utilizando-se para isso de uma abordagem quantitativa.

No tocante ao objetivo proposto a pesquisa constituiu-se como descritiva, mediante a busca da descrição do fenômeno estudado, podendo ser produzida para identificar relações existentes entre variáveis e estudar as características de uma determinada população (GIL, 2010). Assim, enquanto procedimento técnico caracterizou-se como uma pesquisa documental, que utilizou dados secundários para obtenção e formação do banco de dados para a realização do estudo conforme quadro 1. 
10 | Análise da influência de Variáveis Socioeconômicas na distribuição de casos e óbitos de Covid-19 no Brasil

Quadro 1 - Origem dos Dados Secundários

\begin{tabular}{|c|c|}
\hline Dados & Base \\
\hline $\begin{array}{l}\text { IDHM (Municípios, Renda, } \\
\text { Longevidade e Educação) }\end{array}$ & $\begin{array}{l}\text { https://www.ibge.gov.br/cidades-e- } \\
\text { estados.html?view=municipio }\end{array}$ \\
\hline Renda per capita & https://economia.terra.com.br/infograficos/renda/ \\
\hline Aeroportos & $\begin{array}{c}\text { http://www4.infraero.gov.br/ e } \\
\text { https://aeroportosdobrasil.com.br/ }\end{array}$ \\
\hline Regiões Metropolitanas & $\begin{array}{l}\text { https://www.ibge.gov.br/geociencias/organizacao- } \\
\text { do-territorio/estrutura-territorial/18354-regioes- } \\
\text { metropolitanas-aglomeracoes-urbanas-e-regioes- } \\
\text { integradas-de- } \\
\text { desenvolvimento.html?=\&t=downloads }\end{array}$ \\
\hline Óbitos & $\begin{array}{c}\text { https://covid.saude.gov.br/ } \\
\text { https://brasil.io/dataset/covid19/caso/ } \\
\text { https://covid19br.wcota.me/ }\end{array}$ \\
\hline Casos & $\begin{array}{c}\text { https://covid.saude.gov.br/ e } \\
\text { https://brasil.io/dataset/covid19/caso/ } \\
\text { https://covid19br.wcota.me/ }\end{array}$ \\
\hline
\end{tabular}

Fonte: Dados da Pesquisa (2020)

A escolha das variáveis baseou-se em estudos recentes que identificam relações estatísticas entre dados demográficos, socioeconômicos, movimentação e aglomeração urbana com o registro de casos e óbitos por Covid-19 (DAMETTE; GOUTTE, 2020; GILBERT et al., 2020; SANNIGRAHI et al., 2020; RAFAEL et al., 2020; SÁ, 2020; STOJKOSKI et al., 2020; TEIXEIRA et al., 2020; VAHEDI; RIVERA, 2020). A partir da seleção dos dados, foram identificadas variáveis conforme quadro 2, e estas foram analisadas pelo software Statistical Package for Social Sciences (SPSS). 
Quadro 2 - Variáveis Selecionadas

\begin{tabular}{|c|}
\hline Variáveis Selecionadas com base nos Dados Secundários \\
\hline Óbitos por COVID 19 (totais e a cada 100.000 habitantes) \\
\hline Casos de COVID 19 (totais e a cada 100.000 habitantes) \\
\hline IDHM Municípios \\
\hline IDHM Renda \\
\hline IDHM Longevidade \\
IDHM Educação \\
\hline Aeroportos Brasileiros \\
\hline Regiões Metropolitanas do Brasil \\
\hline
\end{tabular}

Fonte: Dados da Pesquisa (2020)

Para o estudo foram definidas as variáveis de análise baseando-se inicialmente na definição da variável dependente, que foi identificada pelo número de óbitos por COVID 19 no Brasil, partindo desta definição verificou-se se variáveis socioeconômicas como IDH influenciam no aumento do número de óbitos no país. Alguns estudos recentes utilizaram o número de óbitos como variável dependente para tentar explicar possíveis relações existentes entre estes números e outras variáveis, como exemplo o estudo de Valenti et al. (2020) e Oliveira (2020) que consideram que as medidas de distanciamento social podem reduzir os dados de incidência de casos e mortes relacionadas à COVID-19 no Brasil.

Considerando essas questões, definiu-se como hipótese inicial $\left(\mathrm{H}_{0}\right)$ que o número de casos não influencia o número de óbitos. Sendo assim, buscou-se identificar e selecionar primeiramente na amostra, os municípios brasileiros com maior número de casos e óbitos e após isto verificar a relação existente entre essas duas variáveis. Após, foram realizados os testes com as demais variáveis que foram selecionadas conforme mostra o quadro 2 (IDHM Municípios, IDHM Renda, IDHM Longevidade, IDHM Educação, os municípios brasileiros com aeroportos e as Regiões Metropolitanas do Brasil). 
Foram utilizados os registros até a data de 02 de junho de 2020. Foi utilizado como variável dependente o número de óbitos ocorridos no Brasil. Assim, para o estudo foram coletados dados de 4.131 municípios na data de 02 de junho de 2020. Destes, foram registradas mortes em 1.758 municípios em um total de 30.520 mortes e 541.734 casos. O tamanho amostral foi definido com $n=200$ municípios que registraram maior número de casos. Os municípios da amostra concentram um total de 18.064 mortes ou 59,19\% dos óbitos por COVID-19 registrados em todo - Brasil. Registra-se também que, nesses municípios selecionados foram registrados 270.695 casos ou $49,97 \%$ dos casos brasileiros no período.

Nessa condição inicial, foi fixado nível de significância de $\alpha=5 \%$, pois esse valor implica valor relevante e significativa da amostra, conforme cálculo amostral. Apresenta uma amostra de $\mathrm{n}=200$, para um universo de 1758 municípios.

A Figura 1 mostra a espacialização da amostra do estudo com o mapa de localização e a distribuição do número de casos nos 200 municípios selecionados, ou seja, na figura 1 é espacializado os municípios e seus respectivos estados de origem para a amostra selecionada no referido estudo. Serve também para visualizar onde há a ocorrência de maior número de mortes.

Identificou-se nos estados de São Paulo (41 municípios), Pará (28 municípios), Rio de Janeiro (23 municípios), Amazonas (18 municípios), Ceará (20 municípios) e Pernambuco (15 municípios), os estados que apresentam o maior número de munícipios na amostra selecionada. São Paulo e Rio de Janeiro são estados localizados na região sudeste do Brasil, fragmento que concentra o maior adensamento populacional. Pará e Amazonas, são estados da região norte. Ceará e Pernambuco pertencem ao nordeste brasileiro. 
Figura 1 - Espacialização da Amostra

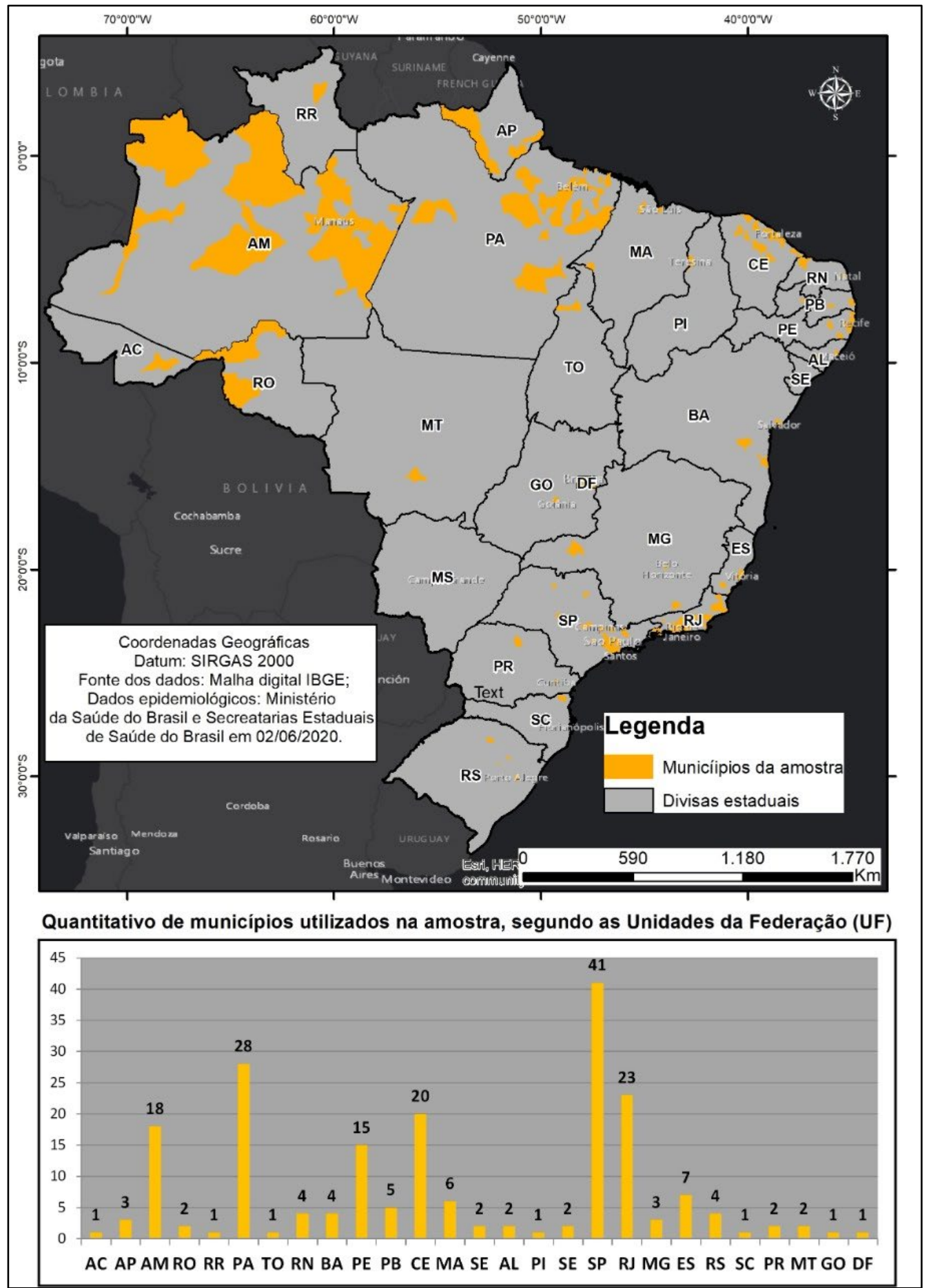

Fonte: Dados da pesquisa (2020)

Com base no objetivo do estudo que é analisar a influência de variáveis socioeconômicas na distribuição de casos e óbitos relacionados ao Covid-19 no Brasil, o estudo verificou também a relação existente entre dados demográficos de IDH, ou seja, variáveis socioeconômicas partindo do IDHM (IDH Municípios, IDHM 
Renda, IDHM Longevidade, IDHM Educação) com dados das cidades que estão localizadas em regiões metropolitanas e que possuem aeroportos. Para justificar o uso das variáveis "aeroporto" e "regiões metropolitanas", o estudo baseou-se na hipótese inicial de que "em regiões metropolitanas o número de casos e óbitos é igual em cidades que não fazem parte de regiões metropolitanas".

Os dados foram processados no SPSS versão 11.0 for Windows e apresentados em tabelas. Realizou-se análise de estatística descritiva univariada (médias, moda e medianas). A fim de verificar a existência de associação entre variáveis, foi efetuada análise bivariada de correlação e nível de significância entre as variáveis e regressão das variáveis com correlação e nível de significância identificadas como fortes e moderadas. Para todos os testes foi fixado o nível de significância de $5 \%$.

Partindo da análise descritiva inicial e de pesquisas recentes que analisam as relações entre o número de casos por Covid-19 com o número de óbitos, além de estudos que buscam analisar variáveis demográficas e geográficas para explicar ou entender as variações do número de casos e óbitos nas diferentes regiões e municípios brasileiros, além dos resultados das correlações e níveis de significâncias obtidos inicialmente pelas análises. Foram formuladas hipóteses iniciais para o presente estudo, conforme quadro 3. 
Quadro 3 - Hipóteses Selecionadas

\begin{tabular}{|c|c|}
\hline Hipóteses & Descrição \\
\hline $\mathrm{H}_{0}$ & O número de casos independe (não influencia) do número de óbitos \\
\hline $\mathrm{H}_{1}$ & Há relação entre o número de casos e o número de óbitos \\
\hline $\mathrm{H}_{2}$ & Quanto menor o IDHM renda maior o número de casos de Covid-19 a \\
cada 100.000 habitantes
\end{tabular}

Fonte: Dados da Pesquisa (2020)

Após foram analisados e obtidos resultados estatísticos a partir da obtenção das médias, medianas, modas, desvio padrão, máximo e mínimo e correlação entre as variáveis. Foi realizado o Teste de Correlação de Pearson (p), o Teste QuiQuadrado ( $\mathrm{X}^{2}$ ) e a Análise de Regressão (R2). Estes resultados serão discutidos na próxima seção.

\section{RESULTADOS}

$\mathrm{Na}$ amostra inicial os dados apontam que 4.148 municípios brasileiros apresentam registros de COVID-19, com 541.734 casos e 30.520 mortes registradas. Os municípios que apresentam os maiores registros de casos, óbitos, casos por $100 \mathrm{mil} / \mathrm{habitantes} \mathrm{e} \mathrm{óbitos} \mathrm{por} 100 \mathrm{mil} /$ habitantes são apresentados nas Tabela 1 , 2,3 e 4. 
16 | Análise da influência de Variáveis Socioeconômicas na distribuição de casos e óbitos de Covid-19 no Brasil

Tabela 1 - Munícipios com mais casos de Covid-19 até 02/06/2020

\begin{tabular}{llll}
\hline Municípios & Estado & Casos & Óbitos \\
\hline São Paulo & São Paulo & 61.126 & 4.304 \\
Rio de Janeiro & Rio de Janeiro & 30.014 & 3.671 \\
Fortaleza & Ceará & 24.104 & 2.084 \\
Manaus & Amazonas & 18.367 & 1.371 \\
Recife & Pernambuco & 15.474 & 1.081 \\
Belém & Pará & 11.885 & 1.335 \\
Salvador & Bahia & 11.431 & 474 \\
Brasília & Distrito Federal & 10.648 & 171 \\
São Luís & Maranhão & 9.447 & 528 \\
Maceió & Alagoas & 6.097 & 288 \\
\hline
\end{tabular}

Fonte: Elaboração própria a partir de dados da pesquisa (2020)

Tabela 2 - Munícipios com mais óbitos por Covid-19 até 02/06/2020

\begin{tabular}{llll}
\hline Municípios & Estado & Óbitos & Casos \\
\hline São Paulo & São Paulo & 4.304 & 61.126 \\
Rio de Janeiro & Rio de Janeiro & 3.671 & 30.014 \\
Fortaleza & Ceará & 2.084 & 24.104 \\
Manaus & Amazonas & 1.371 & 18.367 \\
Belém & Pará & 1.335 & 11.885 \\
Recife & Pernambuco & 1.081 & 15.474 \\
São Luís & Maranhão & 528 & 9.447 \\
Salvador & Bahia & 474 & 11.431 \\
Jaboatão dos & Pernambuco & 318 & 3.190 \\
Guararapes & & 311 & 2.718 \\
Osasco & São Paulo & & \\
\hline
\end{tabular}

Fonte: Elaboração própria a partir de dados da pesquisa (2020) 
Tabela 3 - Munícipios com mais Casos/100.000 habitantes até 02/06/2020

\begin{tabular}{llc}
\hline Municípios & Estado & Casos/100.000 hab. \\
\hline Japurá & Amazonas & 413,793 \\
Serra do Navio & Amapá & 413,192 \\
São Gabriel da Cachoeira & Amazonas & 399,218 \\
Itapiranga & Amazonas & 377,131 \\
Santo Antonio do lça & Amazonas & 330,524 \\
Laranjal do Jari & Amapá & 307,478 \\
Tefé & Amazonas & 306,939 \\
Pedra Branca do Amapari & Amapá & 306,629 \\
Entre Rios & Santa Catarina & 268,498 \\
Amaturá & Amazonas & 267,857 \\
\hline
\end{tabular}

Fonte: Elaboração própria a partir de dados da pesquisa (2020)

Tabela 4 - Munícipios com mais Óbitos por Covid-19/100.000 habitantes até $02 / 06 / 2020$

\begin{tabular}{llc}
\hline Municípios & Estado & Óbitos/100.000 hab. \\
\hline Saldanha Marinho & Rio Grande do Sul & 150,943 \\
Senador José Porfírio & Pará & 102,933 \\
Manacapuru & Amazonas & 95,505 \\
Tefé & Amazonas & 93,568 \\
Curuçá & Pará & 89,851 \\
Belém & Pará & 89,432 \\
Tabatinga & Amazonas & 86,568 \\
Uru & São Paulo & 85,836 \\
Fortaleza & Ceará & 78,071 \\
São Caetano de Odivelas & Pará & 72,022 \\
\hline
\end{tabular}

Fonte: Elaboração própria a partir de dados da pesquisa (2020) 
Partindo dos dados iniciais, foram selecionados os 200 municípios brasileiros onde foram registrados os maiores números de óbitos por Covid-19 no ano de 2020. Assim, este estudo analisa a distribuição de 18.064 (59,19\%) das mortes distribuídos em 27 estados. O total de casos do período analisado foi de 541.734 casos, sendo selecionados $270.695(49,97 \%)$ dos casos.

A Tabela 5 apresenta os dados gerais das variáveis analisadas neste estudo considerando as características dos casos, óbitos, número de aeroportos, municípios pertencentes a regiões metropolitanas e municípios com aeroportos pertencentes a regiões metropolitanas. A Tabela 5 apresenta ainda que dos 200 municípios, 59 (29,50\%) possuem aeroportos e que 121 (60,50\%) estão localizados em regiões metropolitanas e 31 (15,50\%) destes municípios possuem aeroportos e estão localizados em regiões metropolitanas.

Os dados iniciais apresentados são consonantes com alguns estudos que evidenciam origens no processo de contaminação viral, cidades com adensamentos populacionais e com grande movimentação urbana possuem uma tendência em dispersar o vírus para outras regiões, além do que cidades metropolitanas tendem a ter uma maior quantidade de casos e óbitos (BAJARDI et al., 2011; WANG; TAYLOR, 2016; CHARU et al., 2017; DAMETTE; GOUTTE, 2020; SA, 2020). 
Tabela 5 - Dados gerais das variáveis analisadas

\begin{tabular}{lcc}
\hline Variáveis & $\mathbf{N}$ & $\%$ \\
\hline Casos & 541.734 & 100 \\
Totais & 270.695 & 49,97 \\
Selecionados & & \\
Óbitos & 30.520 & 100 \\
Totais & 18.064 & 59,19 \\
Selecionados & & \\
Aeroportos & 59 & 29,50 \\
Sim & 141 & 70,50 \\
Não & 121 & \\
Municípios em Região Metropolitana & 60,50 \\
Sim & 79 & 39,50 \\
Não & 169 & \\
Municípios com Aeroporto e em Região & \\
Metropolitana & & \\
Sim & 31 & \\
Não & & \\
\hline
\end{tabular}

Fonte: Elaboração própria a partir de dados da pesquisa (2020)

Em relação à distribuição espacial do número de casos por estado brasileiro, destaca-se o Estado de São Paulo que apresentou média de casos por município de 2410,78 casos em 41 municípios. Por outro lado, o Estado de Santa Catarina apresentou a menor média de casos por município, com uma média de 423 casos ocorridos em apenas 1 município.

O significativo avanço no número de casos no Brasil e a forma rápida o vírus se espalhou, que segundo dados do Ministério da Saúde em menos de 1 mês o vírus já estava presente em todos os Estados brasileiros e até a data de 02 de junho de 2020, apresenta-se em 4.148 municípios, tem levado estudiosos a buscar entender de que forma ou por quais as principais vias de contágio em 
determinados locais (ALMAGRO; ORANE-HUTCHINSON, 2020; FANG; WANG; YANG, 2020).

Para o número de óbitos pode-se constatar que a média de mortes registradas na pesquisa está próxima de 128 ( mean $=127,57)$. Contudo, como nos mostra a mediana ( median $=36,50$ ), que divide o conjunto em duas partes iguais, sendo o valor modal igual a 18, o que provoca uma fuga de simetria. Assim, a distribuição dos óbitos ( $n=200$ ) é assimétrica à direita, o que significa que a maior concentração de óbitos está na calda inferior da distribuição.

No que se refere à dispersão tem-se que esta amostra é bastante heterogênea em vista do desvio padrão observado (Std. Deviation $=446,25$ ), algo que se confirma ao agregar-se à análise os valores mínimos (Minimium $=11$ ) e máximos (Maximium $=4.304$ ) observados para o conjunto de dados relativos aos óbitos registrados.

Foi realizado um teste inicial de correlação entre as variáveis, Óbitos, Casos, Óbitos por 100 mil habitantes, Casos por 100 mil habitantes, IDH Município, IDHM Renda, IDHM Longevidade, IDHM Educação, Cidade com Aeroportos, Cidade em Regiões Metropolitanas e Cidade em regiões Metropolitanas com aeroportos. Deste teste inicial foram selecionados os que obtiveram melhor índice de correlação e significancia.

Após isso, foi realizado um novo teste de correlação entre essas variáveis, conforme a Tabela 6 que indica a correlação existente entre as variáveis Óbitos, Casos, IDHM Renda, aeroportos internacionais, Municípios em Regiões Metropolitanas, Municípios com aeroportos internacionais e em Regiões Metropolitanas, Casos por 100 mil habitantes e Óbitos por 100 mil habitantes em 200 municípios brasileiros com maior número de mortes registrados até o dia 02 de junho de 2020. 
Tabela 6 -Dados gerais das variáveis analisadas

\begin{tabular}{|c|c|c|c|c|c|c|c|c|c|c|c|c|}
\hline & & IDHM & IDHM_R & IDHM_L & IDHM_E & AERO & RM & $\begin{array}{c}\text { AERO_R } \\
M\end{array}$ & $\begin{array}{l}\text { OBITOS } \\
-100 \mathrm{~K}\end{array}$ & $\begin{array}{l}\text { CASOS } \\
-100 \mathrm{~K}\end{array}$ & ÓBITOS & CASOS \\
\hline IDHM & $P$ & 1,000 & & & & & & & & & & \\
\hline IDHM_L & $\mathrm{P}$ & $0,904 * *$ & $0,979 * *$ & 1,000 & & & & & & & & \\
\hline IDHM_E & $P$ & $0,962 * *$ & $0,875^{* *}$ & $0,820 * *$ & 1,000 & & & & & & & \\
\hline RM & $\mathrm{P}$ & 0,400 & $0,366 * *$ & $0,328 * *$ & $0,418 * *$ & $-0,105$ & 1,000 & & & & & \\
\hline AERO_RM & $P$ & $0,329 * *$ & $0,362 * *$ & $0,157^{*}$ & $0,326 * *$ & $0,662 * \star$ & $0,346 * \star$ & 1,000 & & & & \\
\hline $\begin{array}{c}\text { OBITOS_100 } \\
\mathrm{K}\end{array}$ & $\mathrm{P}$ & $-0,532 * \star$ & $-0,536^{* *}$ & $-0,493 * *$ & $-0,490 * *$ & 0,000 & $-0,030$ & $-0,064$ & 1,000 & & & \\
\hline CASOS_100K & $P$ & $-0,535 * \star$ & $-0,511 * *$ & $-0,548 * *$ & $-0,500 * *$ & 0,035 & $-0,168^{*}$ & 0,028 & $0,705^{* *}$ & 1,000 & & \\
\hline
\end{tabular}

Fonte: SPSS, a partir de dados da pesquisa (2020)

* Correlação fraca

** Correção moderada/forte

Como resultado da análise da tabela 6, pode-se inferir que, existe correlação forte, com significância estatística $(p<0,05)$ entre o número de casos totais e $o$ número de óbitos totais $\left(\rho=0,747^{* *}\right)$. Já entre o número de casos ocorridos e regiões metropolitanas com aeroportos, apresenta correlação moderada, com significância estatística $(\rho=0,479 * *)$. Há ainda, correlação moderada com significância estatística $(p<0,05)$ entre o número de casos ocorridos em cidades em regiões metropolitanas $(\rho=0,319 * *), \operatorname{IDHM}(\rho=0,377 * *), \operatorname{IDHM}$ Renda $(\rho=$ $0,389 * *)$ e IDHM Educação $(\rho=0,372 * *)$. 
Entre a variável número de óbitos com as demais, observa-se correlação moderada com significância estatística existente com as variáveis IDHM ( $\rho=$ $\left.0,368^{* *}\right)$, IDHM Renda $(\rho=0,361 * *)$, IDHM Longevidade $(\rho=0,323 * *)$, IDHM Educação $\left(\rho=0,373^{* *}\right)$, cidades em regiões metropolitanas $(\rho=0,460 * *)$, cidades em regiões metropolitanas com aeroportos $\left(\rho=0,402^{* *}\right)$ e regiões metropolitanas há relação de correlação moderada e significância $\left(\rho=0,460^{* *}\right)$. Isto pode ser explicado devido os casos iniciais de COVID-19 no Brasil terem origem internacional e em cidades metropolitanas e que possuem aeroportos, ou seja, em cidades com IDHM mais alto.

Quando analisado o número de casos por 100 mil habitantes e óbitos por 100 mil habitante com as demais variáveis, observa-se que para algumas variáveis como cidades com aeroportos, cidades em regiões metropolitanas e cidades em regiões metropolitanas com aeroportos, os testes não apontam correlação com significância estatística entre as variáveis, como observado na figura 2. Os resultados iniciais mostram que os maiores números de casos e óbitos por 100.000 habitantes relacionados à Covid-19 estão predominantemente fora das regiões metropolitanas dos estados, revelando assim indícios de disseminação e intensificação da doença pelos municípios do interior.

Em relação às variáveis de IDHM (Renda, Longevidade e Educação) percebese que estas possuem correlação positiva moderada e significante tanto com o número de casos, quanto em relação ao número de óbitos (Figura 2). Em relação às variáveis de IDHM (Renda, Longevidade e Educação) relacionadas com as variáveis casos por 100 mil habitantes e óbitos por 100 mil habitantes, observa-se correlação negativa moderada com significância estatística (figura 2). Assim mais uma vez é observado indícios de que os maiores números de casos e óbitos por 100.000 habitantes relacionados à Covid-19 estão predominantemente fora das regiões metropolitanas dos estados, revelando mais uma vez indícios de disseminação e intensificação da doença pelos municípios do interior. 
Com isso, A partir das hipóteses selecionadas foram realizados testes de hipóteses e de regressão linear para cada variável correlacionada inicialmente, ao nível de significância a = 5\%. Inicialmente para as variáveis "casos" e óbitos", o valor observado no Teste de Correlação de Pearson $(\rho=0,957)$, pode-se concluir assim que, existe uma forte correlação positiva entre as variáveis e que, em função disto, as duas variáveis tendem a variar de modo dependente de modo que se deve rejeitar a hipótese $\mathrm{H}_{0}$ (O número de casos independe do número de óbitos).

Nos dados relativos à distribuição normal dos casos, da tabela cruzada "Óbitos" e "Casos" observa-se que o valor do qui-quadrado $\left(X^{2}\right)$ é igual a 17607,590 com significância $p<0,01$. Ainda nesta direção é percebida e que à medida que cresce o número de "Casos", cresce o número de "Óbitos", em que apresenta ( $p$ < 0,0001). Assim, com base nos valores apresentados no SPSS rejeita-se a hipótese nula, ou seja, há evidências estatísticas de que existe associação entre as variáveis testadas.

Para a $\mathrm{H}_{0}$ (o número de casos independe do número de mortos), através do teste de regressão realizado infere-se que o teste apresentou $R^{2}=0,726$ entre as variáveis óbitos (dependente) e casos (independente). Neste caso, pode-se dizer que, na análise, o número de "casos" explica em 72,6\% a variação no número de "óbitos", com significância $(p<0,01)$. A regressão linear simples mostra que o número de casos influencia o número de mortos através da ANOVA $[F(1,198)=$ $\left.523,399, p<0,01 ; R^{2}=0,726\right]$. Assim, o modelo pode ser explicado pela equação $y$ $=-0,961+0,895$. (casos). Com base nas análises e demonstrações pode-se rejeitar $H_{0}$ (o número de casos independe do número de óbitos) de pesquisa de que há correlação entre as duas variáveis e aceita-se a hipótese $H_{1}$ (há relação entre o número de casos e o número de óbitos).

Esta análise inicial em relação às variáveis "casos" e "óbitos", parece inicialmente ser óbvia pois quanto maior o número de casos maior poderá ser o quantitativo de mortos, porém esse dado inicial é relevante para demonstrar estatisticamente a proximidade desta relação e provocar a discussão sobre 
medidas que promovam a redução do número de casos, como aumento do isolamento social, diminuição do movimento urbano, melhoria das condições de renda, higiene e saúde da população e até mesmo medidas extremas como o lockdown em bairros, cidades, estados ou em um país. Essas e outras medidas que promovam a redução do número de casos, terão como consequência a redução do número de vidas ceifadas por Covid-19.

Para $\mathrm{H}_{2}$ "Quanto menor o IDHM Renda maior o número de casos e óbitos a cada 100.000 habitantes" e $\mathrm{H}_{3}$ "Quanto menor o IDHM Renda maior o número de óbitos por Covid-19 a cada 100.000 habitantes" com base nos testes de Correlação de Pearson, pode-se concluir que existe uma correlação moderada entre as três variáveis uma vez que o valor observado no Teste de Correlação de Pearson ( $\rho$ = 0,469) para "Óbitos por 100 mil habitantes" e "IDHM Renda" e $(\rho=-0,420)$ para "Casos por 100 mil habitantes" e "IDHM Renda". Ambas apresentam nível de correlação negativa e significância $(p<0,05)$ e que, em função disto, as variáveis tendem a variar de modo dependente de modo que inicialmente deve-se aceitar a hipóteses $\mathrm{H}_{2}$ e $\mathrm{H}_{3}$ de pesquisa de que há correlação negativa entre as variáveis.

A partir dos dados relativos à distribuição normal dos casos, da tabela cruzada entre "Casos por 100 mil habitantes" e "IDHM_Renda" e entre "Óbitos por 100 mil habitantes" e "IDHM_Renda", observa-se para a primeira variável que o valor do qui-quadrado ( $\left.X^{2}\right)$ é igual a 31000,000 com significância estatística. Para as variáveis "Óbitos por 100 mil habitantes" e "IDHM_Renda" observa-se o valor do qui-quadrado ( $\left.X^{2}\right)$ é igual a 30850,000 com significância estatística.

Quando a análise usa dados total de casos e óbitos, os resultados relativos à distribuição normal dos casos, da tabela cruzada entre "Casos" e "IDHM Renda" e entre "Óbitos" e "IDHM Renda", observa-se para a primeira variável o valor observado no Teste de Correlação de Pearson $(\rho=0,267)$ e que o valor do quiquadrado $\left(X^{2}\right)$ é igual a 27913,889, com $p<0,05$. 
Para as variáveis "Óbitos" e "IDHM Renda" o valor observado no Teste de Correlação de Pearson $(\rho=0,240)$ e que o valor do qui-quadrado $\left(X^{2}\right)$ é igual a 14625,545. Ainda nesta direção é percebida que na análise não há significância estatística entre as variáveis $(p=0,108)$.

Foi realizado o teste de regressão bivariada entre as variáveis "Óbitos" (dependente) e "Casos" e "IDH_Renda" (independente). O teste apresentou R² = 0,728. Neste caso, pode-se dizer que, na análise, o número de "casos" e "IDH_Renda" explica em 72,8\% a variação no número de "óbitos", com significância $(p<0,01)$, em que também pode ser explicada pela equação $y=-0,813+(0,871) b+(0,461) c$, em que b (casos) e c (IDH_Renda). Assim, com base nas análises e demonstrações, pode-se aceitar a hipótese $\mathrm{H} 2$ de pesquisa de que há correlação entre as duas variáveis.

Observa-se que, os resultados tanto para o cruzamento entre "casos" e "óbitos" com "IDHM Renda" e entre "casos por 100 mil habitantes" e "óbitos por 100 mil habitantes" com "IDHM Renda" possuem valores diferentes e opostos em relação aos níveis de correlação e significância. Assim, identifica-se mais uma vez uma relação negativa com significancia $(p<0,05)$ entre as variáveis “Óbitos por 100 mil habitantes", "Casos por 100 mil habitantes" e "IDHM Renda", aceitando-se as hipóteses $\mathrm{H}_{2}$ e $\mathrm{H}_{3}$ de pesquisa de que há correlação negativa entre as variáveis. Identifica-se também uma relação entre as variáveis "Óbitos", "Casos" e "IDHM Renda", porém uma relação positiva e mais fraca que na análise anterior.

No tocante às hipóteses $\mathrm{H}_{2}$ e $\mathrm{H}_{3}$, cabe ressaltar que a relação entre as variáveis casos e óbitos por Covid-19 a cada 100.000 habitantes e o IDHM Renda não se comporta de maneira homogênea ao longo do território brasileiro. Existe, de fato, em grande parte dos casos da amostra uma relação inversamente proporcional entre IDHM Renda e os dados epidemiológicos por 100.000 habitantes ligados a Covid-19, contudo foram verificadas situações distintas para dois grandes grupos territoriais. 
A partir da Figura 2, é possível visualizar na porção Norte do Brasil um predomínio de municípios com IDHM Renda baixo e elevado número de casos de Covid-19 por 100.000 habitantes, ao passo que na porção Centro-Sul do Brasil, verifica-se o predomínio de municípios com elevado IDHM Renda e baixo número de casos de Covid-19 a cada 100.000 habitantes.

Em razão de um menor quantitativo populacional na porção Norte-Nordeste (sobretudo no estado do Amazonas), há uma proporção maior de casos de Covid19 comparativamente a grande parte da amostra localizada na porção Centro-Sul do país (de maior concentração populacional). O avanço da Covid-19 para esses municípios com menor IDHM Renda localizados, principalmente na porção NorteNordeste pode ter um impacto maior do que para os municípios localizados na porção Centro-Sul (IDHM Renda mais elevado), em razão da capacidade de enfrentamento às consequências da pandemia. 
Figura 2 - Casos de Covid-19 a cada 100.000 hab.02/06/2020 e IDHM Renda (2010) para os municípios da amostra.
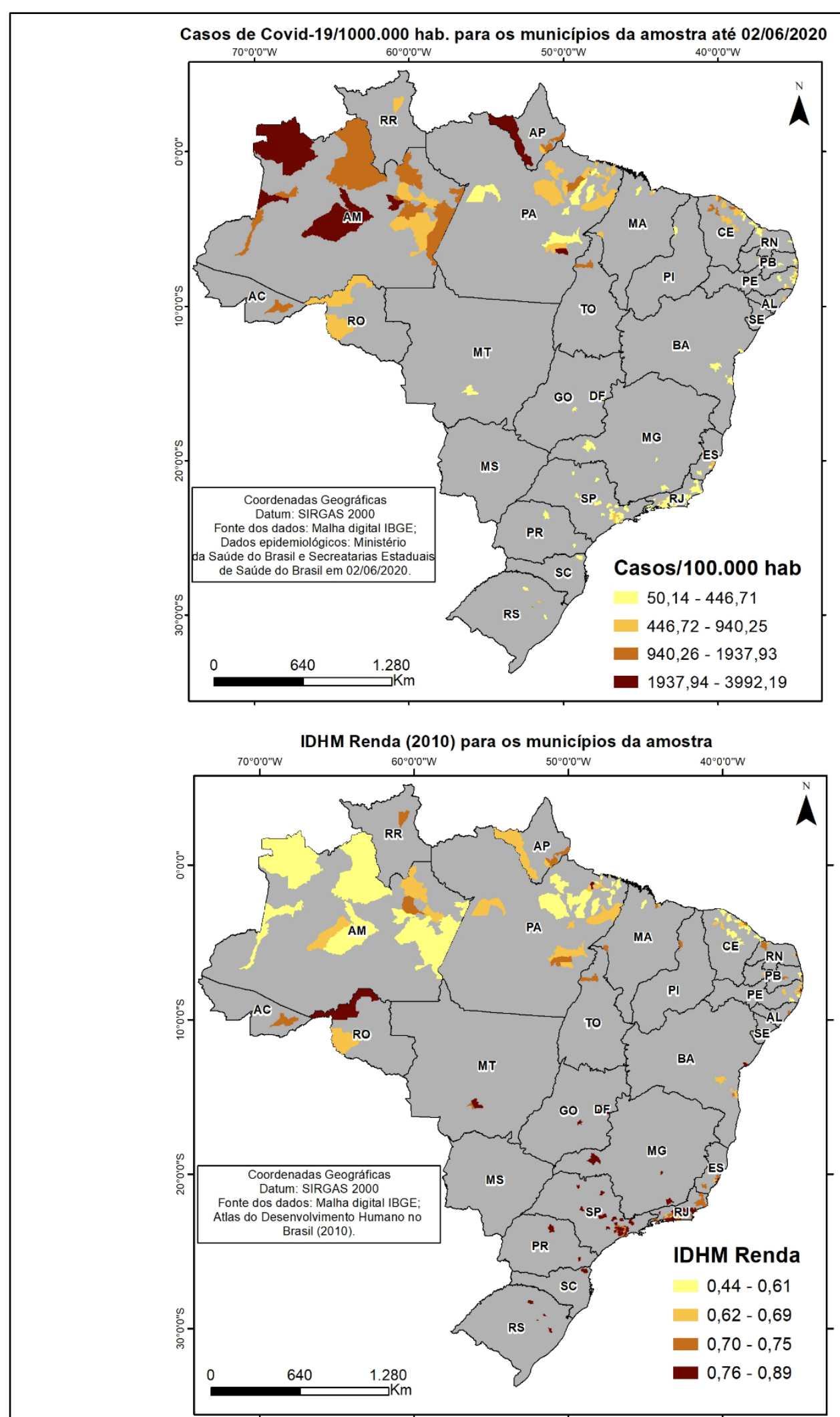

Fonte: Elaborado pelos autores com base em dados da pesquisa (2020) 
Uma avaliação sobre a capacidade de enfrentamento a essa nova realidade epidemiológica pode ser realizada a partir da razão da quantidade de óbitos a cada 100.000 habitantes. Para os dados de óbitos por Covid-19 a cada 100.000 habitantes, verifica-se uma variação espacial quantitativa semelhante à variação identificada para a distribuição quantitativa dos casos de Covid-19 a cada 100.000 habitantes.

A porção territorial Norte apresenta predominantemente na amostra municípios com elevados números de óbitos a cada 100.000 habitantes e baixo valor de IDHM Renda, ao passo que na porção territorial Centro-Sul ocorre o predomínio de uma situação inversa, com baixos números relativos de óbitos por Covid-19 e altos valores para a variável IDHM renda, conforme exposto por meio da Figura 3. 
Figura 3- Óbitos por Covid-19 a cada 100.000 habitantes e IDHM Renda (2010) para os munícipios da amostra até 02/06/2020.

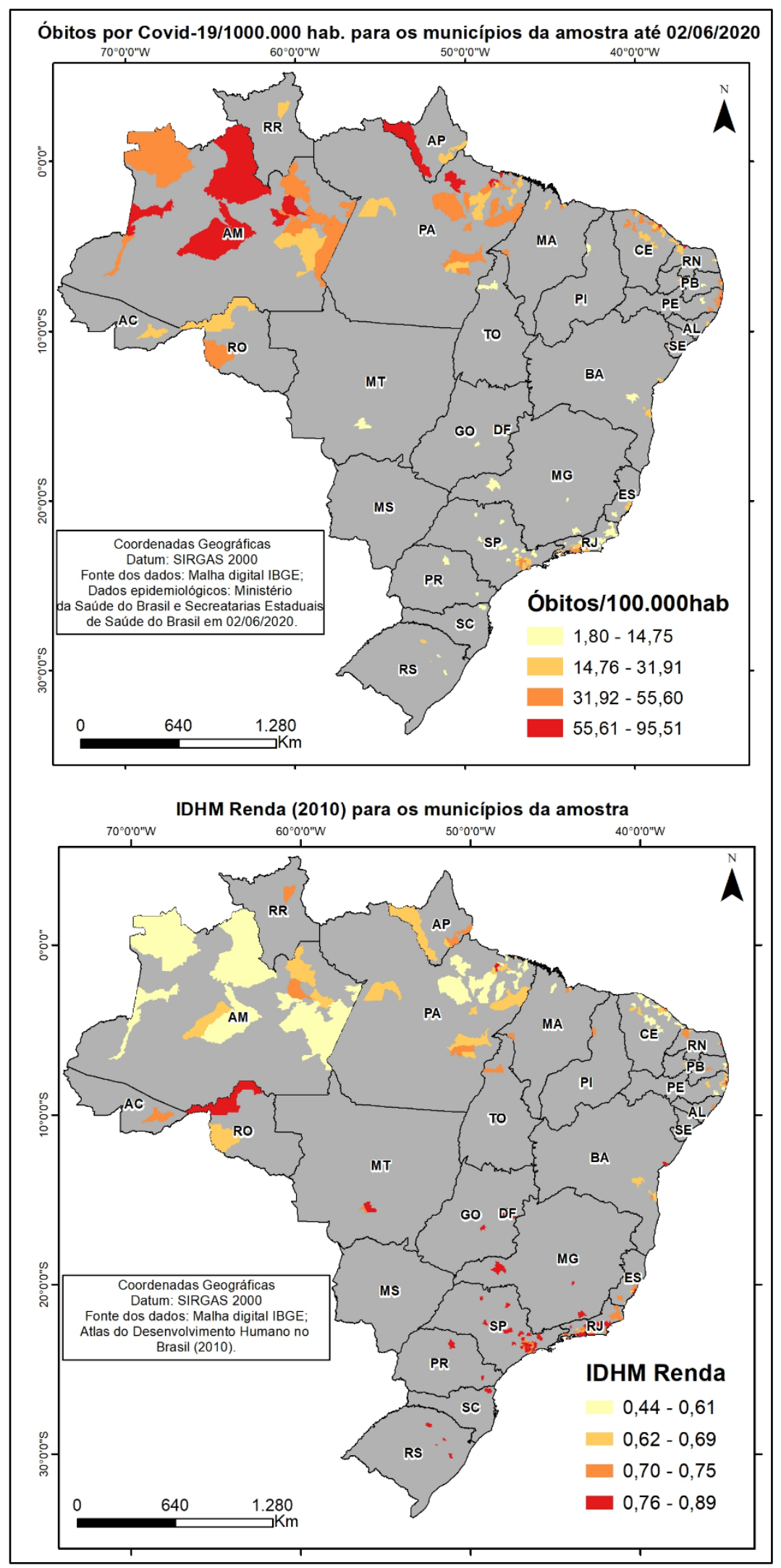

Fonte: Elaborado pelos autores com base nos dados da pesquisa (2020) 
Essas diferenças regionais também são verificadas na razão de médicos por mil habitantes. De acordo com o estudo "Demografia Médica no Brasil, 2018" (SCHEFFER et al., 2018), em janeiro de 2018 o Brasil possuía 452.801 médicos, sendo correspondente a uma razão de 2,18 médicos por mil habitantes. Essa razão é comparável a países como Estados Unidos $(2,6)$ e Japão $(2,4)$, no entanto no Brasil constata-se ainda uma considerável desigualdade na distribuição dessa população médica entre regiões, estados, capitais e municípios do interior.

Segundo Scheffer et al. (2018, p. 43): "enquanto em todo o País existem 2,18 médicos por mil habitantes, há capitais com mais de 12 médicos por mil habitantes - como Vitória, no Espírito Santo - e regiões do interior do Nordeste com valores inferiores a um médico por mil habitantes." Em relação à distribuição dos médicos, segundo as Grandes Regiões brasileiras, as regiões Norte e Nordeste apresentam a menor proporção de médicos por mil habitantes, com 1,16 e 1,41, respectivamente. A região Sudeste apresenta a melhor proporção de médicos por mil habitantes $(2,81)$, seguida das regiões Centro-oeste $(2,36)$, Sul $(2,31)$.

Além de questões relativas à capacidade do sistema de saúde para o enfrentamento à Covid-19, destaca-se ainda: um possível isolamento social deficitário em razão da necessidade de obtenção de meios para sobrevivência e/ou pelo baixo conhecimento quanto à prevenção ao contágio pela Covid-19, que pode se constituir como fator para ampliação da vulnerabilidade/exposição à essa doença para a população de menor renda. Além disso, com o relativo grande número de casos, há a tendência de redução da oferta de leitos de internação, com um consequente aumento da dificuldade para o acesso, sobretudo para a população com menor renda, ao serviço de saúde pública. Tais elementos contribuem para explicar o aceite para as hipóteses $\mathrm{H}_{2}$ e $\mathrm{H}_{3}$.

Para a hipótese H4 “O número de óbitos e casos de Covid-19 a cada 100.000 habitantes é maior em cidades localizadas em regiões metropolitanas", nos resultados relativos à distribuição normal dos casos, da tabela cruzada entre 
"Óbitos por 100 mil habitantes" e "Cidades localizadas em regiões metropolitanas" observou-se que no Teste de Correlação de Pearson não se observou correlação estatisticamente significativa $(p>0,05)$. No segundo teste, onde foram analisadas as variáveis "Casos por 100 mil habitantes" e "cidades localizadas em regiões metropolitanas" o resultado apresentou uma correlação fraca e negativa ( $\rho=$ $0,200)$ com significância $(p=0,005)$.

Apesar de existir correlação entre casos por 100 mil habitantes e sua ocorrência em cidades localizadas em regiões metropolitanas, os dados e o mapa apresentado na Figura 4, evidenciam que no período atual tanto o quantitativo de casos como de óbitos tende a crescer em cidades interioranas. Assim, com os dados apresentados do estudo, rejeita-se a hipótese $\mathrm{H} 4$ "O número de óbitos e casos de Covid-19 a cada 100.000 habitantes é maior em cidades localizadas em regiões metropolitanas", pois apesar dos números absolutos de casos e óbitos serem maiores em cidades localizadas em regiões metropolitanas, proporcionalmente em números relativos (casos e óbitos por 100 mil habitantes) não foi verificada esta relação.

A partir da Figura 4 é possível visualizar a distribuição de óbitos a cada 100.000 habitantes nos 200 municípios selecionados para a amostra. Com exceção da Região Metropolitana de Manaus/AM, todas as outras aglomerações metropolitanas ou apresentaram baixa incidência de óbitos em termos proporcionais às suas populações ou ainda não possuíam municípios selecionados para a amostra.

Para a $\mathrm{H}_{5}$ (Cidades que possuem aeroportos e estão em regiões metropolitanas, possuem maior número de casos e óbitos a cada 100.000 habitantes relacionados à Covid-19 que as demais), nos resultados relativos à distribuição normal dos casos, da tabela cruzada tanto na análise entre "Óbitos por 100 mil habitantes" e "Cidades localizadas em regiões metropolitanas com aeroportos" e entre "Casos por 100 mil habitantes" e "Cidades localizadas em 
regiões metropolitanas com aeroportos" os resultados do Teste de Correlação de Pearson não apresentaram correlação estatisticamente significativa $(p>0,05)$.

Mais uma vez, com base nos resultados, verificou-se que os maiores números de casos e óbitos por 100.000 habitantes relacionados à Covid-19 estão predominantemente fora das regiões metropolitanas dos estados, independente dessas cidades ou regiões possuírem aeroportos, o que revela indícios de disseminação e intensificação da doença pelos municípios do interior na data de corte do estudo e que embora o número relativo de casos de Covid-19 seja elevado para municípios fora das Regiões Metropolitanas, essas podem também experimentar o impacto da disseminação dessa doença pelos municípios interioranos, uma vez que concentram grande parte dos serviços hospitalares de alta complexidade, como as Unidades de Terapia Intensiva (UTI). 
Figura 4- Óbitos por Covid-19 a cada 100.000 nos municípios da amostra em 02/06/2020 e Regiões Metropolitanas.

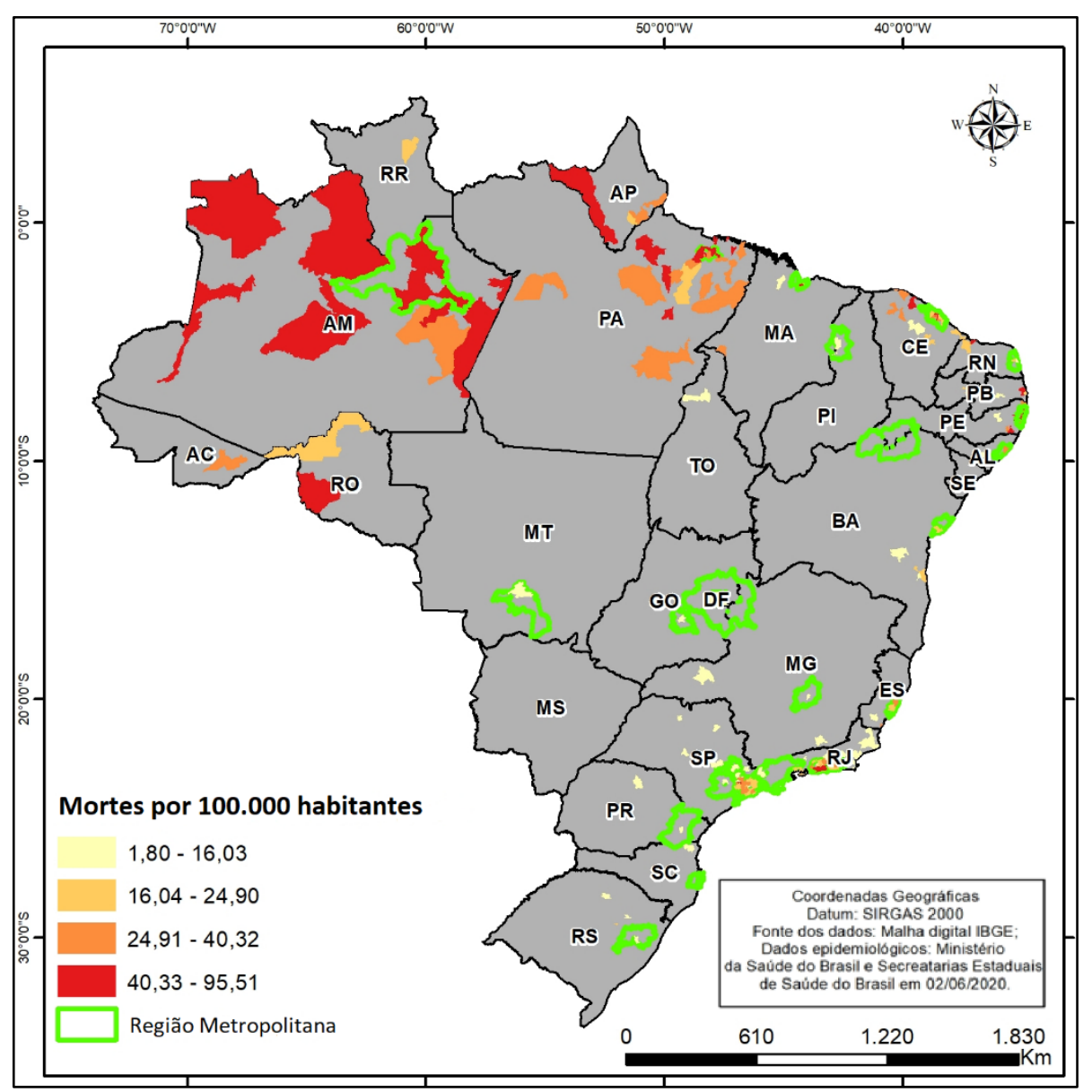

Fonte: Elaborado pelos autores com base nos dados da pesquisa (2020)

Com base nos resultados é possível inferir que na data de referência dos dados epidemiológicos utilizados (02/06/2020), a proximidade de aeroportos internacionais não foi relevante, tendo em vista que os casos e óbitos estão se disseminando para os municípios interioranos. Até a data de referência dos dados, 1.578 municípios apresentavam registros de óbito e 4.148 registraram casos relacionados à Covid-19, o que demonstra uma ampla disseminação da doença no território brasileiro. Caso os dados de referência para a pesquisa fossem de um recorte temporal mais próximo ao primeiro caso de Covid-19 registrado no Brasil (26/02/2020) possivelmente a influência dos aeroportos internacionais poderia ser demonstrada de forma evidente quanto à distribuição de casos e óbitos relativos a esse vírus. 


\section{CONSIDERAÇÕES FINAIS}

Em síntese, em meio à atual situação de crise mundial relativa à epidemia de Covid-19, observa-se a necessidades de estudos atuais e abrangentes sobre o tema. Surge assim a proposta deste estudo que objetivou analisar a influência de variáveis socioeconômicas na distribuição de casos e óbitos relacionados a Covid19 no Brasil, observando para isso relações estatísticas entre variáveis sociais relacionadas ao IDHM (IDH Municípios, IDHM Renda, IDHM longevidade e IDHM Educação), de concentração populacional (identificada pelas regiões metropolitanas), de mobilidade interurbana e interestadual /internacional (aeroportos) com variáveis associadas aos números de casos e óbitos por COVID19 no território brasileiro.

Nessa perspectiva, a pesquisa se propôs a ser uma contribuição que adotou como base a análise estatística inferencial, aplicando a produção de mapas baseados nos dados secundários coletados para o estudo. Dessa forma, foram analisadas as relações entre variáveis sociais relacionadas ao IDHM, de mobilidade interurbana e interestadual /internacional (aeroportos) com variáveis associadas aos números de casos e óbitos por COVID-19, testando-se para isso hipóteses que pudessem identificar e auxiliar na compreensão dessas relações.

Como resultado, a análise das variáveis selecionadas permitiu identificar relações entre as hipóteses HO (O número de casos independe do número de óbitos), H2 (Quanto menor o IDHM renda maior o número de casos de Covid-19 a cada 100.000 habitantes) e H3 (Quanto menor o IDHM renda maior o número de óbitos por Covid-19 a cada 100.000 habitantes). Além disso, foram identificados através de mapas e padrões de distribuição espacial a relação entre as variáveis que explicam as hipóteses aceitas e que se complementam com as hipóteses rejeitadas H1 (Há relação entre o número de casos e o número de óbitos ), H4 (O número de óbitos e casos de Covid-19 a cada 100.000 habitantes é maior em cidades localizadas em regiões metropolitanas) e H5 (Cidades que possuem 
aeroportos e estão em regiões metropolitanas, possuem maior número de casos e óbitos a cada 100.000 habitantes relacionados à Covid-19 que as demais). Esses padrões espaciais verificados através distribuição espacial de casos, óbitos, aeroportos no território nacional facilitam um entendimento do estudo realizado.

Observa-se que os resultados apresentados se referem aos registros oficiais datados até 02 de junho de 2020 e que em um estudo temporal mais próximo aos primeiros casos de Covid-19 registrados no Brasil (26/02/2020), possam explicar a influência de aeroportos com voos domésticos e internacionais em relação à distribuição e disseminação de casos e óbitos relativos a Covid-19 no Brasil.

Essa pesquisa foi realizada com um enfoque nacional para o entendimento geral das relações entre variáveis sociais, como IDHM e variáveis de mobilidade e aglomeração urbana. Assim, abrem-se novas oportunidades de estudos a partir da atualização diária dos dados, da disseminação de casos e óbitos nos municípios brasileiros, análises locais de disseminação do vírus que relacionem mobilidade urbana e interurbana, além da análise temporal e perspectivas análises considerando heterogeneidade e homogeneidades entre os municípios e suas características sociais e urbanas.

Assim, estudos futuros que apresentem análises com dados evolutivos da pandemia para os próximos meses podem ampliar o entendimento da evolução da COVID-19 no território brasileiro e servir de modelo para análise da evolução pandêmica e da influência de variáveis socioeconômicas em outros territórios. Torna-se necessário com isso, estudos que usem ou associem outras variáveis como demográficas (raça, concentração populacional, gênero) e espaciais a variáveis socioeconômicas não somente para entender o contexto atual da pandemia, mas também para o desenvolvimento de políticas públicas que diminuam possíveis influências negativas dessas variáveis sobre a sociedade em contexto de futuras pandemias. 


\section{REFERÊNCIAS}

ALMAGRO, M. E ORANE-HUTCHINSON, A. Os determinantes da exposição diferencial ao COVID19 na cidade de Nova York e sua evolução ao longo do tempo. Covid Economics: Vetted e Real-Time Papers, (13), $2020 . \quad$ Disponível em: https://malmagro.github.io/Covid_and_Within_City_Inequality.pdf. Acesso em: 30. Maio. 2020.

ATKESON, A. Quão mortal é a covid-19? compreender as dificuldades com a estimativa de sua taxa de mortalidade ( $n^{\circ}$ w26965). 2020. Bureau Nacional de Pesquisa Econômica. Disponível em: https://www.nber.org/papers/w26965. Acesso em: 05. Junho. 2020.

BAJARDI, P., POLETTO, C., RAMASCO, JJ, TIZZONI, M., COLIZZA, V. E VESPIGNANI, A. Redes de mobilidade humana, restrições de viagens e a disseminação global da pandemia de H1N1 em 2009. Plos um, 6 (1), e16591, 2011. Disponível em: https://journals.plos.org/plosone/article/file?type=printable\&id=10.1371/journal.pone. 001659 1. Acesso em: 30. Maio. 2020.

BARRETO, M. L. et al. O que é urgente e necessário para subsidiar as políticas de enfrentamento da pandemia de COVID-19 no Brasil? Revista Brasileira de Epidemiologia, v. 23, n. 23, p. 1-4, 2020.

CHARU, V. et al. Human mobility and the spatial transmission of influenza in the United States. PLoS computational biology, 13 (2), e1005382. 2017. Disponível em: https://journals.plos.org/ploscompbiol/article/file?id=10.1371/journal.pcbi.1005382\&type=pri ntable. Acesso em: 30. Maio. 2020.

COVEN, J.; GUPTA, A. Disparities in mobility responses to covid-19. NYU Stern Working Paper, 2020. Disponível em: https://static1.squarespace.com/static/56086d00e4b0fb7874bc2d42/t/5ebf201183c6f016ca3a bd91/1589583893816/DemographicCovid.pdf. Acesso em: 30. Maio. 2020.

DAMETTE, O. GOUTTE, S. The macroeconomic determinants of Covid19 mortality rate and the role of post subprime crisis decisions. 2020. Disponível em SSRN: https://ssrn.com/abstract=3610417. Acesso em: 30. Maio. 2020.

DORN, A. VAN; COONEY, R. E.; SABIN, M. L. COVID-19 exacerbating inequalities in the US. The Lancet, v. 10232, p. 1242-1244, 2020.

FANG, H.; WANG, L.; YANG, Y. Human mobility restrictions and the spread of the novel coronavirus (2019-ncov) in china. National Bureau of Economic Research. 2020. Disponível em: https://www.nber.org/papers/w26906.pdf. Acesso em: 30. Maio. 2020. 
FARIA, R, M. et al. Difusão espacial e interiorização da COVID-19 no Estado do Rio Grande do Sul. Revista da Casa da Geografia de Sobral, Sobral/CE, v. 22, n. 2, p. 26-43, Ago. 2020, https://doi.org/10.35701/rcgs.v22n2.686.

GIL, A. C. Métodos e técnicas de pesquisa social. 5. reimpr. São Paulo: Atlas, v. 201, 2010.

GILBERT, M. et al. (2020). Preparedness and vulnerability of African countries against importations of COVID-19: a modelling study. The Lancet, 395 (10227), 871-877, 2020.

GUIMARÃES, R. M.; ELEUTERIO, T. de A.; MONTEIRO-DA-SILVA, J. H. C. Estratificação de risco para predição de disseminação e gravidade da Covid-19 no Brasil. Revista Brasileira de Estudos de População, v. 37, 2020.

JONES, C. et al. A note on efficient mitigation policies. Covid Economics, 4, 25-46, 2020. Disponível em: https://cepr.org/sites/default/files/news/CovidEconomics4.pdf. Acesso em: 05. Junho. 2020.

MACEDO, Y. M. COVID-19: Situação dos infectados e mortos na América do Sul. Boletim de Conjuntura (BOCA), 2 (5), 73-84, 2020.

MOLLALO, A., VAHEDI, B. E RIVERA, K. M. Modelagem espacial baseada em GIS da taxa de incidência de COVID-19 nos Estados Unidos continentais. Ciência do Ambiente Total, 138884. 2020.

OLIVEIRA, C. A. Ficar em casa salva vidas? uma estimação dos impactos do isolamento social nos casos e nos óbitos por covid-19 registrados no Brasil. 2020. Recuperado em 06 junho de 2020.Disponível

em: https://www.researchgate.net/profile/Cristiano_Oliveira10/publication/341135386_Does_stayi ng_at_home_saves_lives_An_estimation_of_the_impacts_of_social_isolation_in_the_registered_ cases_and_deaths_by_Covid-19_in_Brazil/links/5eb09cf645851592d6b94434/Does-staying-athome-saves-lives-An-estimation-of- os-impactos-do-isolamento-social-nos-casos-registradose-mortes-por-Covid-19-no-Brasil.pdf.

ORELLANA, J. D. Y. et al. Excesso de mortes durante a pandemia de COVID-19: subnotificação e desigualdades regionais no Brasil. Cadernos de Saúde Pública, v. 37, p. e00259120, 2021.

RAFAEL, R. D. M. R. et al. Effect of income on the cumulative incidence of COVID-19: an ecological study. Revista Latino-Americana de Enfermagem, 28, 2020.

ROWTHORN, R. Uma análise de custo-benefício da doença de Covid-19. Covid Economics, 9, 97-106, 2020. Disponível em: https://cepr.org/sites/default/files/news/CovidEconomics9.pdf. Acesso em: 05. Juho. 2020.

SÁ, F. Socioeconomic Determinants of COVID-19 Infections and Mortality: Evidence from England and Wales. 2020. Disponível em SSRN: https://ssrn.com/abstract=3612850. Acesso em: 05. Junho. 2020. 
SANNIGRAHI, S. et al. A mortalidade geral causada pela covid-19 na região europeia está altamente associada à composição demográfica: uma abordagem baseada em regressão espacial. Pré-impressão do arXiv arXiv: 2005.04029, 2020.

SANTOS, J. P. C. et al. Vulnerabilidade a formas graves de COVID19: uma análise intramunicipal na cidade do Rio de Janeiro, Brasil. Cad. Saúde Pública, v. 36, n. 5, p. 1-12, 2020.

SCHEFFER, M. et al. Demografia Médica no Brasil 2018. São Paulo, SP: FMUSP, CFM, Cremesp, 2018. 286 p. ISBN: 978-85-87077-55-4. Disponível em: http://jornal.usp.br/wpcontent/uploads/DemografiaMedica2018.pdf. Acesso em: 11. junho. 2020.

STOJKOSKI, V. et al. Os determinantes socioeconômicos da pandemia de doença por coronavírus (COVID-19). Pré-impressão do arXiv arXiv: 2004.07947. 2020.

TEIXEIRA, S. Indicadores de casos e óbitos pelo COVID-19 e sua relação com fatores contextuais: um estudo ecológico na cidade de Natal-RN / Indicadores de casos e óbitos pelo COVID-19 e sua relação com fatores contextuais: um estudo ecológico na cidade de Natal -RN. Revista Brasileira de Desenvolvimento, 6 (6), 40689-40703, 2020.

VALENTI, V. E. et al. Medidas de distanciamento social podem ter reduzido as mortes estimadas relacionadas à COVID-19 no Brasil. J Hum Growth Dev, v. 30, n. 2, p. 164-169, 2020.

WANG, Qi; TAYLOR, J. E. (2016). Patterns and limitations of urban human mobility resilience under the influence of multiple types of natural disaster. PLoS one, v. 11, n. 1, 2016. Disponível em: https://www.ncbi.nlm.nih.gov/pmc/articles/PMC4731215/pdf/pone.0147299.pdf. Acesso em: 30. Maio. 2020.

WANG, Z.; TANG, K. Combating COVID-19: health equity matters. Nature Medicine, v. 26, p. 458-464, 2020.

\section{1 - Marco Túlio Mendonça Diniz:}

Professor Associado da Universidade Federal do Rio Grande do Norte - UFRN, Doutor em Geografia pela Universidade Estadual do Ceará - UECE

https://orcid.org/0000-0002-7676-4475 - tuliogeografia@gmail.com

Contribuição: Referencial teórico, interpretação e análise dos dados, escrita e revisão do texto

\section{2 - Marcos Antonio Cavalcante de Oliveira Júnior:}

Professor Efetivo do Instituto Federal do Piauí - IFPI, Mestre em Geografia pelo Instituto Federal do Piauí - IFPI

https://orcid.org/0000-0003-0630-4913, marcos.cavalcante@ifpi.edu.br Contribuição: Tabulação dos dados, análise e geração dos dados estatísticos, interpretação e análise dos dados, escrita e revisão do texto. 


\section{3 - Vítor Hugo Campelo Pereira:}

Doutor em Geografia pela Universidade Federal do Rio Grande do Norte - UFRN https://orcid.org/0000-0002-8550-7016, vitor.pereira95@yahoo.com.br Contribuição: Revisão do texto, cartografia e construção dos mapas, interpretação e análise dos dados, escrita e revisão do texto.

\section{4 - Glairton Cardoso Rocha:}

Professor Efetivo do Ins Instituto Federal do Piauí - IFPI, Doutor em Geografia pela Universidade Estadual Paulista - UNESP

https://orcid.org/0000-0002-1706-7338, glairtongeo@ifpi.edu.br Contribuição: Referencial teórico, interpretação e análise dos dados, escrita e revisão do texto.

\section{Como citar este artigo}

DINIZ, M. T. M.; OLIVEIRA JUNIOR, M. A. C de; PEREIRA, V. H. C.; ROCHA, G. C. Análise da influência de Variáveis Socioeconômicas na distribuição de casos e óbitos de Covid-19 no Brasil. Geografia Ensino \& Pesquisa, Santa Maria, v. 25, e43, p. 1-37, 2021. DOI 10.5902/2236499461365. Disponível em: https://doi.org/10.5902/2236499461365. Acesso em: dia mês abreviado. ano. 